Proceedings of SALT 23: $1-18,2013$

\title{
Response particles as propositional anaphors ${ }^{1}$
}

\author{
Manfred Krifka \\ Humboldt-Universität Berlin \\ \& Zentrum für Allgemeine Sprachwissenschaft (ZAS) Berlin
}

\begin{abstract}
The paper explains response particles like yes and no as anaphoric elements that pick up propositional discourse referents that are introduced by preceding sentences. It is argued that negated antecedent clauses introduce two propositional discourse referents, which results in ambiguities of answers that are partly resolved by pragmatic optimization. The paper also discusses response particles like okay, right, uh-huh, uh-uh, and German ja, nein and doch.
\end{abstract}

Keywords: response particles, polarity particles, discourse referents

For example, the single words "yes" or "no," when coming at the end of a protracted discussion, may have an extraordinarily great significance. Transmission of Information, R.V.L. Hartley, 1928.

\section{Introduction}

There is a - perhaps naïve - conviction that response particles, also called polarity particles, like yes and no are particularly simple and straightforward, as the following quote from the gospel of St. Matthew (King James translation) shows.

(1) But let your communication be, Yea, yea; Nay, nay; for whatsoever is more than these cometh of evil.

(Matthew 5:37)

To think of yes and no as simple may be reasonable for responses to assertions and questions as in (2). But things get messy with responses to antecedents that contain a negation as in (3), where different continuations with elliptical clauses are possible.

1 This work was supported by Bundesministerium für Bildung und Forschung (Förderkennzeichen 01UG0711) and Deutsche Forschungsgemeinschaft (SFB 632 Informationsstruktur). Thanks to the audience at various presentations of preliminary versions of this paper, including the Workshop "Variables at the Interface between Form and Meaning" of the SFB 833 at Tübingen in July 2012, a presentation at ZAS in Berlin in December 2012, at the Sklarszka Poreba meeting in March 2013, and at Rutgers University in April 2013. Special thanks to Manfred Bierwisch, Arik Cohen, Sophia Döring, Donka Farkas, Hans-Martin Gärtner, Andreas Haida, Clemens Mayr, Edgar Onea, Paul Portner, Sophie Repp, Floris Roelofsen, Philippe Schlenker, Heiko Seeliger, Emilio Servidio, Todd Snider, Hubert Truckenbrodt, Tue Trinh, Kazuko Yatsushiro and Malte Zimmermann for valuable suggestions.

(C) 2013 Krifka 
Response particles as propositional anaphors
(2) a. A: You stole the cookie.
b. A: Did you steal the cookie?
B: Yes. (= B did steal the cookie)
No. (= B didn't steal the cookie)
(3) A. Aou did not steal the cookie.
b. A: Did you not steal the cookie?
$\begin{array}{cr}\text { B: Yes. } & \text { B: Yes, I didn't. / Yes, I did. } \\ \text { No. } & \text { No, I didn't. / No, I did. }\end{array}$

I will present a theory that maintains that the semantics of response particles is simple; however, complications arise due to the negation in the antecedent clause.

\section{Recent approaches to response particles}

The semantics and pragmatics of response particles have been a topic of research interest for a number of years. Here, I will discuss two recent approaches, Kramer \& Rawlins 2009 and Farkas \& Roelofsen (ms.) 2012.

\subsection{Kramer \& Rawlins 2009}

Kramer \& Rawlins analyze yes and no as adverbials corresponding to the heads of ellipsis clauses of category $\Sigma \mathrm{P}$ (the "prejacent"), which in turn correspond to contextually salient propositions. Contextually recoverable parts can be deleted.

(4) A: Ede stole the cookie.

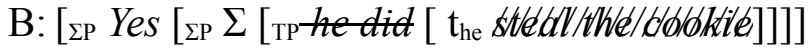

The response particle no has an uninterpretable feature [u NEG] that agrees with the head $\Sigma$ of the elliptical clause, which corresponds to the interpretable negation within the elliptical clause. Being uninterpretable, this feature does not result in a double negation reading in (5) (cf. Zeijlstra 2004).

(5) A: Ede did not steal the cookie.

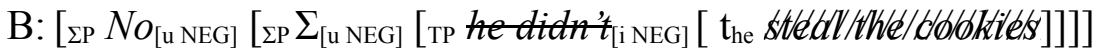

In contrast, the response particle yes is featureless, allowing for the following use in addition to the one mentioned in (4):

(6) A: Ede did not steal the cookie.

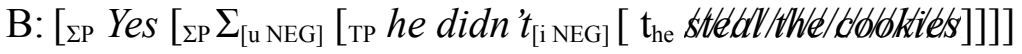

One problem of this account is that it predicts the answer (7) to be possible. Another problem is that the distribution of elliptical clauses with and without response particles is different in embedded contexts, as in (8):

(7) A: Ede stole the cookie. B: "Yes, he didn't sttedtlthelbloblkile.

(8) Did Ede steal the cookies? a. If he did, he must pay them back.

b. *If yes, he did, he must pay them back.

c. If ??yes / so, he must pay them back. 
Krifka

\subsection{Semantic approach: Farkas \& Roelofsen 2012}

Farkas \& Roelofsen 2012 couch their theory within inquisitive semantics and the theory of communication in Farkas \& Bruce 2010. Glossing over details, assertions makes salient one proposition, cf. (9), whereas polarity questions introduce two propositions, one the negation of the other, as in Hamblin semantics, cf. (10).
a. Ede stole the cookies.
$\{\varphi\}$
b. Ede did not steal the cookies.
$\{\neg \varphi\}$
a. Did Ede steal the cookies? $\quad\{\boldsymbol{\varphi}, \neg \varphi\}$
b. Did Ede not steal the cookies? $\{\varphi, \neg \varphi\}$

It is assumed that one of the propositions is highlighted (here represented by boldface); this is the proposition mentioned by the sentence, which provides the target of the response particles. The response particles have the following semantics:
a. yes: confirms highlighted proposition; reverses (= negates) highlighted negative propositions.
b. no: confirms highlighted negative proposition; reverses (= negates) highlighted propositions.

This predicts the answer patterns in (2) and (3). However, notice that (11) requires two devices extraneous to the truth-conditional semantics of questions: the highlighting of propositions, and their identification as negated (as suggested in Situation Semantics, cf. Ginzburg \& Sag 2000, Cooper \& Ginzburg 2011). Farkas \& Roelofson 2012 are aware of this deficiency of purely truth-conditional representations, and suggest in passing the use of propositional discourse referents marked for negation; this will be a crucial feature of the account presented here.

(11) is just a preliminary generalization. In their official theory, Farkas \& Roelofson assume just like Kramer \& Rawlins 2009 that the anaphoric link to the antecedent clause is provided by a prejacent clause, cf. (12).

$$
\text { [Antecedent clause] ... [PolP [Pol yes/no] [ст Prejacent]] }
$$

Furthermore, the two particles are analyzed as a disjunctive feature combination:

(13) a. Absolute Polarity: $[+] /[-]$, prejacent non-negated / negated

b. Relative Polarity: [SAME]/[REVERSE], polarity of prejacent same / reverse

(14) a. yes realizes $[\mathrm{samE}]$ or $[+]$

b. no realizes [REVERSE] or [-]

This explains the answering patterns in (3) as in (15) and (16):

(15) A: Did Ede steal the cookies?
B: a. [PolP yes [SAME] or [+] $[\mathrm{CP}$ he did.]]

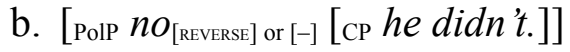


Response particles as propositional anaphors

(16) A: Did Ede not steal the cookies?
B: a. [PolP yes ${ }_{[\mathrm{SAME}]}[\mathrm{CP}$ he didn't.]]
b. [PolP $y e s_{[+]}[\mathrm{cP}$ he did.] $]$

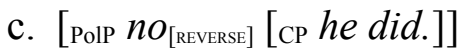
d. [PolP $n o_{[-]}[\mathrm{CP} h e$ didn't. $]$

Farkas \& Roelofsen apply their feature system to response particles in other languages, such as French si and German doch as [REVERSE, +] particles and Romanian $b a$ as a particle marking [REVERSE] in combination with other particles.

This theory avoids problem (7) due to the formulation of the conditions where yes can be used. It can also circumvent problem (8) by concentrating on yes and $n o$ in their response function only. But to my mind, the characterization of yes and $n o$ by disjunctive features in (14) is fairly complex. In the theory proposed in the following, suggestions by Farkas \& Roelofson that response particles are anaphoric expressions are worked out in greater detail, and the complexity that we observe in the use of these particles will be explained as resulting from independently motivated complexities in the way their antecedents are introduced.

\section{Response particles as anaphora}

\subsection{Propositional discourse referents}

In the theory proposed here, response particles are not related to a prejacent clause that is anaphoric to an antecedent clause, but they are anaphors themselves. That is, they pick up discourse referents that are anchored to salient propositions. Such propositional discourse referents have been assumed by a number of authors, e.g. by Asher 1986, Cornish 1992, Geurts 1998 and Frank 1996. For example, propositions can be taken up by pronouns, as in (17):

$$
\begin{aligned}
& {[\text { Ede stole the cookie]. Bill knows }[i t] .} \\
& \hookrightarrow \mathrm{d}_{\text {prop }}
\end{aligned} \uparrow \mathrm{d} \quad \hookrightarrow \text { : introduction, } \uparrow \text { : uptake }
$$

The first clause introduces a propositional discourse referent $d$ that is anchored to the proposition 'Ede stole the cookie'. It is picked up by the pronoun it and interpreted as the argument of the propositional attitude verb know.

Clauses can also introduce other kinds of discourse referents, in particular discourse referents anchored to events, as in (18), or to speech acts, as in (19).

(18) Ede stole the cookie. Bill saw it.

(19) A: Ede stole the cookie. B: That's a lie!

I propose that the three types of clausal discourse referents are introduced by three distinct layers in the clause. Events are introduced by the vP, semantically an event predicate, like $\lambda \mathrm{e}$ [e is an event of Ede stealing the cookie]. Propositions claim that an event exists in a temporal or modal relation to a world-time index, like $\lambda \mathrm{i} \exists \mathrm{e}$ [e is an event in the world of $\mathrm{i}$ preceding the time of $\mathrm{i}$, and $\mathrm{e}$ is an event 
of Ede stealing the cookie]; this corresponds to the syntactic category TP. In a speech act like an assertion, a speaker takes on responsibility for the truth of a proposition; this change of commitments of a speaker corresponds to a change of the world (cf. Szabolcsi 1982). This change is an event as well. I assume that this corresponds to a distinct layer in syntax, which I call ActP. (20) and (21) illustrate this with an assertion and a polarity question. ${ }^{2}$

$$
\begin{aligned}
& \text { [ActP ASSERT [тр Ede steal-PAST [vр } \mathrm{t}_{\text {Ede }} \mathrm{t}_{\text {steal }} \text { the cookie]]] } \\
& \hookrightarrow \mathrm{d}_{\text {speech act }} \quad \hookrightarrow \mathrm{d}_{\text {prop }}^{\prime} \quad \hookrightarrow \mathrm{d}^{\prime \prime}{ }_{\text {event }} \\
& \text { (21) [ActP } d i d-Q U E S T \text { [тр } E d e t_{\text {did }}-P A S T \text { [vр } t_{\text {Ede }} \text { steal the cookie]]] } \\
& \hookrightarrow \mathrm{d}_{\text {speech act }} \quad \hookrightarrow \mathrm{d}_{\text {prop }}^{\prime} \quad \hookrightarrow \mathrm{d}^{\prime \prime}{ }_{\text {event }}
\end{aligned}
$$

Negation creates a propositional syntactic category, which I will call NegP. ${ }^{3}$ This also introduces a propositional discourse referent, which is anchored to the proposition $\lambda \mathrm{i} \neg \exists \mathrm{e}[\mathrm{e}$ is an event in the world of $\mathrm{i}$ and before the time of $\mathrm{i}$, and $\mathrm{e}$ is an event of Ede stealing the cookie].

$$
\begin{aligned}
& \text { [ActP ASSERT [NegP Ede did-n't [Tт } \mathrm{t}_{\mathrm{Ede}} \mathrm{t}_{\mathrm{did}}\left[{ }_{\mathrm{vP}} \mathrm{t}_{\mathrm{Ede}} \mathrm{t}_{\text {steal }}\right. \text { steal the cookie]] } \\
& \rightarrow \mathrm{d}_{\text {speech act }} \quad \rightarrow \mathrm{d}_{\text {prop }}^{\prime} \quad \rightarrow \mathrm{d}_{\text {prop }}^{\prime \prime} \rightarrow \mathrm{d}^{\prime \prime}{ }_{\text {event }}
\end{aligned}
$$

Negation blocks discourse referents that are existentially bound in its scope; hence the event discourse referent $\mathrm{d}^{\prime \prime \prime}$ is not accessible, and continuations like Bill saw it are not possible. But the discourse referent $\mathrm{d}^{\prime \prime}$ remains accessible even under negation, as it is not existentially bound. Evidence for the accessibility of two propositional discourse referents after negation comes from cases like $(23 a, b)$ :

$$
\begin{aligned}
& \text { Two plus two isn't five. } \\
& \text { [NegP } \left.2+2 i s-n ' t\left[{ }_{\text {TP }} t_{2+2} t_{\text {is }} 5\right]\right] \\
& \rightarrow \mathrm{d}^{\prime}{ }_{-[2+2=5]} \rightarrow \mathrm{d}_{[2+2=5]} \\
& \text { a. Everyone knows that. } \\
& \uparrow \mathrm{d}^{\prime}{ }_{-[2+2=5]} \\
& \text { b. That would be a contradiction. } \\
& \uparrow \mathrm{d}_{[2+2=5]}
\end{aligned}
$$

The first clause introduces two propositional discourse referents, $\mathrm{d}$ for the proposition $2+2=5$, and $\mathrm{d}^{\prime}$ for its negation, $\neg[2+2=5]$. (23a) obviously picks up $\mathrm{d}^{\prime}$, whereas (b) picks up d. Example (24) makes the same point with the pronoun it.

$$
\begin{aligned}
\text { Ede didn't steal the cookie, } & \text { a. and he actually can prove it. } \\
& \text { b. even though people believed it. }
\end{aligned}
$$

It is worthwhile to notice that the introduction of a propositional discourse referent for the non-negated proposition depends on the presence of a syntactic cate-

2 The examples do not represent a movement of Ede to SpecActP and of steal-PAST to Act ${ }^{0}$.

3 It is often assumed that NegP is a category under TP, following Pollock 1989. The main argument is that NPIs do not occur in subject position. However, negation clearly scopes over tense; Ede didn't steal the cookie says that within the reference time, there was no stealing event, not that there was an event that was not a stealing. 
Response particles as propositional anaphors

gory expressing negation. This is lacking in (25), and reference to the non-negated proposition becomes much harder.

(25) Two plus two is unequal to five. a. Everyone knows that.
[тр 2+2 is unequal 5]
b. ${ }^{\#}$ That would be a contradiction.

$\hookrightarrow \mathrm{d}_{[2+2 \neq 5]}$

Example (26) makes the same point. While the first clause in (b) entails that the Incas did not reach Tahiti, this proposition does not result in a discourse referent.

(26) a. The Incas didn't reach Tahiti, even though Heyerdahl claimed this. b. \#The Incas missed Tahiti, even though Heyerdahl claimed this.

Negative quantifiers behave like sentential negation, introducing a non-negated proposition. In (27), this refers to 'someone has deciphered Rongorongo'.

(27) Nobody has ever deciphered Rongorongo, the writing of Easter Island, even though this has sometimes been claimed.

The examples given here show that we have to assume discourse referents for sentential objects, to explain the interpretation of anaphoric pronouns like it and that. Now, what are the semantic objects that these discourse referents are anchored to? A minimal view is that they are anchored to propositions that just capture the truth value of clauses, as in Heim 1992. A maximal view is that they stand for full-fledged representational objects, as in Asher 1986. An intermediate view is that they consist of propositions plus a sequence of discourse referents, the ones that are introduced by the clause that expresses that proposition, as in Frank 1996 and Geurts 1998. This representation is necessary, as pronouns referring to propositional discourse referents can make accessible the discourse referents introduced by indefinite expressions in their scope, as in the following example:

Ede probably didn't buy a car. And if this were true, he would have sold $\underline{i t}$.

We assume that propositional discourse referents that are introduced by a NegP receive a formal feature [neg]. This is a feature similar to gender in gender languages. E.g. in German, a discourse referent introduced by eine Gabel 'a fork' has to be marked as [feminine], and is picked up by an agreeing pronoun, sie. In a similar way, as suggested by Farkas \& Roelofson 2012, discourse referents introduced by negated clauses are formally marked as negative, as in (29); this will determine the range of particles that can pick up such discourse referents, e.g. the German particle doch; see below.

$$
\begin{aligned}
& \text { [NegP Ede did-n't [TP } \mathrm{t}_{\mathrm{Ede}} \mathrm{t}_{\mathrm{did}} \text { steal the cookie]] } \\
& \hookrightarrow \mathrm{d}_{\text {prop[neg] }}^{\prime} \quad \hookrightarrow \mathrm{d}_{\text {prop }}
\end{aligned}
$$

Before we turn to the choice of particles we will have a closer look at the pronominal expressions that pick up propositional discourse referents. 
Krifka

\subsection{Propositional anaphora: DPs, TPs and ActPs}

We have seen examples of pronouns and demonstratives like it, this and that that are able to take up propositional discourse referents. In addition to these anaphoric expressions of category DP, there are anaphoric expressions that appear to be of category TP, namely so and not (pace Cornish 1992, who considers so in this function an adverbial). For example, they occur in if clauses and as complements of propositional attitude verbs like believe, where a category TP is expected:

(30) a. Did Ede steal a cookie? If \{he stole one / so /*this\}, he must give it back.

b. Did Ede steal a cookie? Bill believes \{he stole one / so / this\}.

The verb believe also allows for a DP complement, cf. believe the rumor that..., and so we also find propositional DP anaphors like this in that position.

I would like to propose that yes and no are also anaphors that pick up propositional discourse referents; this corresponds to Ginzburg \& Sag 2000, who call them "propositional lexemes" (however, they analyze these particles as adverbials). In contrast to so, yes and no are of the type ActP. In particular, I assume the following:

(31) a. yes picks up salient propDR d and asserts it: ASSERT(d)

b. no picks up salient propDR $\mathrm{d}$ and asserts its negation: $\operatorname{ASSERT}(\neg \mathrm{d})$

We cannot assume that yes and no simply pick up a propositional discourse referent $d$ because they do not easily fit into syntactic slots reserved for TPs:

(32) a. Did Ede steal a cookie? If ?'yes, he must give it back.

b. Did Ede steal a cookie? Bill believes ?"yes.

Interestingly, this is different for the particles ja and nein in German, which occur freely in such contexts, and hence have to be analyzed as TPs:

(33) a. Hat Ede einen Keks gestohlen? Wenn ja, muss er ihn zurückgeben.

b. Hat Ede einen Keks gestohlen? Bill glaubt, ja / nein.

Hence we have to assume that the particles $j a$ and nein pick up a propositional discourse referent, which then can be asserted. For English yes and no, the assertion is already part of the meaning itself:
a. English: $\llbracket[$ ActP yes $] \rrbracket=\operatorname{ASSERT}(\mathrm{d})$
b. German: $\mathbb{[}\left[{ }_{\text {ActP }} \operatorname{ASSERT}\left[{ }_{\text {тр } j a]} j \rrbracket=\operatorname{ASSERT}\left(\left[{ }_{\text {тр } j a])}=\operatorname{ASSERT}(\mathrm{d})\right.\right.\right.\right.$.

As a consequence, the notion "response particle" makes sense for English yes and no, but not necessarily for German. In German, the particles ja and nein can be used for responses, as in (34)(b), but they don't have to, as in (33).

In contrast to Kramer \& Rawlins 2009 and Farkas \& Roelofsen 2012, I do not assume that yes and no form expressions that stand in construction with prejacent 
Response particles as propositional anaphors

clauses. Structures like yes, he did or no, he didn't rather are analyzed as appositives, consisting of two parallel speech acts. In (35) the answer yes (a), the answer he did (b) and the complex answer yes, he did (c) are given for illustration.

$$
\begin{aligned}
& \text { A: [ActP } d i d \text {-QUEST [TP Ede } t_{\text {did }}-P A S T \text { [vp } t_{\text {Ede }} t_{\text {steal }} \text { the cookie]]] } \\
& \rightarrow \mathrm{d}_{\text {prop }} \quad \rightarrow \mathrm{d}_{\text {event }}^{\prime} \\
& \uparrow \mathrm{d}_{\text {event }}^{\prime} \quad \uparrow \mathrm{d}_{\text {event }}^{\prime}
\end{aligned}
$$

c. [ActP yes], [ActP ASSERT [те he did [[vP the the $\uparrow \mathrm{d}_{\text {prop }} \quad \uparrow \mathrm{d}_{\text {event }}{ } \quad \uparrow \mathrm{d}_{\text {event }}^{\prime}$

The categorial difference between English and German response particles leads to a minimal contrast that should be mentioned here:

A: Does Ede steal cookies?

B: a. [ActP yes], [ActP ASSERT [тр sometimes [тр the does]]]

b. ?'Sometimes [ActP yes]]

(37) A: Stiehlt Ede Kekse?

B: a. [ActP ASSERT [тр ja]], [ForcepASSERT [те manchmal [те

b. [ActP ASSERT [тр manchmal [те ja]]]

The response sometimes yes is hardly acceptable, in contrast to yes, sometimes. This can be derived from the fact that the quantifier sometimes does not easily scope out of the speech act (except in a reading difficult to obtain, meaning 'sometimes the answer is yes'). In contrast, German allows for both options, in particular for manchmal ja. This is predicted if $j a$ is a propositional TP, over which the quantifier sometimes can scope (with the meaning: the proposition 'Ede steals cookies' is true at some indices).

The idea that response particles take up propositional functions may be seen as problematic in what Servidio 2012 calls "polarity fragments", in Italian:
A: Chi di voi ha cenato?
B: Gianni sì. / Gianni no.
'Who among you has eaten?'
'Gianni yes.' / 'Gianni no.'

Answers like Gianni sì can be construed as evidence for the deletion approach of Kramer \& Rawlins, where sì would be the remnant of si, ha cenate 'yes, s/he ate'. For the anaphoric theory, we can assume that the question introduces a propositional discourse referent for each felicitous answer. Alternatively, si and no can pick up the background of the question (cf. Krifka 2001), $\lambda x$ [x has eaten], and apply it to the topic, e.g. Gianni. Polarity fragment answers also occur as partial answers to questions like Gli bambini hanno già cenato? 'Did the children eat al- 
ready?'; here the response particle may take up the proposition 'the children have eaten', which is restricted by the free topic, Gianni.

\subsection{Other ways of responding}

The focus of this article is on the response particles yes and no, but it should be noted that there are other ways of responding to an assertion. Here, I will give a quick overview of how some prominent ways to respond can be dealt with.

One option is to use modal adverbials like maybe. I assume that they are remnants of elliptical clauses, as illustrated in (39).

$$
\begin{gathered}
\text { B: [ActP ASSERT [тр maybe [тр he stole the eookie]]] } \\
\qquad \mathrm{d}_{\mathrm{prop}}
\end{gathered}
$$

Responses like yes maybe appear to be degraded, as if the speaker would weaken an assertion previously made. This can be explained if yes already consists of an unmodified assertion, cf. (40) - the first part asserts d, the second $\diamond$ d. Incidentally, this is additional evidence against the analysis of Kramer \& Rawlins 2009.

(40) \#[ActP yes] [ActP ASSERT [тр maybe [тр the stole the eookie]]]

However, answers like maybe yes, maybe no, and their combination maybe yes maybe no, are well attested. Presumably maybe can act as an operator on the speech act level, similar to adverbials like frankly. With it, the speaker qualifies the assertion, roughly "The right answer could be yes". This signals that there are reasons to give this answer, but perhaps not compelling ones. The analysis of maybe as an evidential that is interpreted above the speech act level, as illustrated in (41), should also be available as an alternative for (40).

$$
\text { [ActP } m a y b e[\text { ActP yes]] }
$$

Answers like (42) are pragmatically incoherent because the first assertion is attenuated, while the other one is unqualified. Just as (40), this is not predicted by Kramer \& Rawlins 2009.

$$
\text { \#[ActP maybe [ActP yes]] [ActP ASSERT [TP he did steal the cookie]] }
$$

In German, response particles may be combined with aber 'but', as in aber ja/nein/doch, which is expected if the adversative conjunction aber applies to TPs or to ActPs (English equivalents roughly are oh yes/no, with an interjection oh that is outside the ActP). Aber expresses some contrast to the targeted speech act. This allows the use of aber in responses to assertions $(43)(a, b)$, and biased questions, $(\mathrm{d}, \mathrm{e})$, but disfavors it for non-biased questions, cf. (c).
a. A: Ede hat Kekse gestohlen.
B: Aber nein. / Aber ja.
b. A: Ede hat keine Kekse gestohlen.
B: \# Aber nein. / Aber ja/doch.
c. A: Hat Ede Kekse gestohlen?
B: (?)Aber nein. /?Aber ja. 
Response particles as propositional anaphors
d. A: Hat denn Ede Kekse gestohlen?
B: 'Aber nein. / Aber ja.
e. A: Hat Ede nicht Kekse gestohlen?
B: Aber nein. /?Aber ja.

The effects are fairly subtle, especially for (c), as the antecedent question can easily be shifted to a biased reading, and then aber is fine. The adversative particle expresses a connotation like: How could you even think of this (the biased) possibility! The results are reminiscent to the more robust effects of the Romanian particle $b a$, analyzed in Farkas 2010 as involving prejacent propositions.

Another speechact related response option is by right and wrong. These particles arguably do not take up a propositional discourse referent, but rather the discourse referent introduced by a speech act, and evaluate it as being justified or not. The evaluation as right states that the speech act was justified, e.g. that the speaker would also commit to the asserted proposition. Consequently, right (and wrong) only allow for one reading for antecedent sentences that are negated, as in (44), which proposes two distinct analyses for right as remnant of an elliptical clause or as a response particle with the same overall meaning.

$$
\begin{aligned}
& \text { A: [ActP ASSERT [NegP Ede did-n't [ } \mathrm{t}_{\mathrm{Ede}} \mathrm{t}_{\mathrm{stal}} \text { steal the cookie]]] } \\
& \rightarrow \mathrm{d}_{\text {speechact }} \\
& \text { B: a. [ActP ASSERT [this is right / wrong]] } \\
& \text { } \uparrow \mathrm{d} \\
& \quad \text { b. [ActP Right.], making the same speech act as d, performed by B. }
\end{aligned}
$$

Naturally, right and wrong are awkward with non-biased questions; all that they could mean in this context is that the act of posing the questions was justified or not. With biased questions, right and wrong apply to the assertion of the proposition that the question is biased to. We can understand this in such a way that the speaker of a biased question, like the declarative question Ede stole a cookie?, influences the addressee to make the corresponding assertion, here Ede stole the cookie. The response right then expresses that this attempt is justified, which is tantamount to saying that the addressee actually would make this assertion.

Yet another type of response is by okay (according to the OED, first recorded mention in 1839 as an acronym of all known). Just like right, it cannot answer a non-biased question, and hence should react to the speech act rather than to the proposition of an antecedent clause. As a consequence, just as right, it never targets the inner proposition in a negated sentence. But it does not commit the utterer to the proposition expressed by the speech act itself (Farkas, pers. comm.). With okay, speaker B just indicates compliance with what speaker A wants, namely that the proposition becomes part of the common ground.

This meaning of okay can be captured if we assume that an assertion consists of two separate operations (cf. also Krifka, to app.): first, a conversational move in which the speaker commits to the truth of the proposition, and second, one in which the speaker intends to make the proposition part of the common ground. These two moves would introduce distinct discourse referents. This is illustrated 
in (45), where the ASSERT operator is expressed by the conjunction of two simpler moves, CM for the event of creating A's commitment to the proposition 'Ede stole the cookie', and CG for the event of A's attempt to make this proposition part of the current common ground of A and B ("putting the proposition on the table", in the terminology of Farkas \& Bruce 2010).

$$
\begin{gathered}
\mathrm{A}:\left[{ } _ { \mathrm { ActP } } \mathrm { CM } \& \mathrm { CG } \left[\mathrm{TP} \text { Ede stole [vP } \mathrm{t}_{\text {Ede }} \mathrm{t}_{\text {steal }}\right.\right. \text { the cookie]]] } \\
\hookrightarrow \mathrm{d}_{\mathrm{sa}} \hookrightarrow \mathrm{d}_{\mathrm{sa}}^{\prime} \hookrightarrow \mathrm{d}^{\prime \prime}{ }_{\text {prop }} \hookrightarrow \mathrm{d}^{\prime \prime \prime}{ }_{\text {event }}
\end{gathered}
$$

B: a. [ActP Right.], making the same speech act as $\mathrm{d}+\mathrm{d}^{\prime}$, performed by B.

b. [ActP Okay.], expressing compliance to the speech act d'.

The compliance meaning of okay also explains the use of okay as a reaction to imperatives, in which the speaker performs a speech act that restricts the future option space of the addressee (e.g. A: Open the window! B: Okay.).

It appears that yes can also be used to indicate compliance to the act CG. This would explain the use of yes (and no) as reactions to imperatives. It could also explain an observation by Paul Portner (pers. comm.) that yes, while fine as a reaction to a question, is slightly dispreferred over yes plus an elliptical clause as a reaction to an assertion:
a. A: Ede stole the cookie.
B: ?Yes. / Yes, he did.
b. A: Did Ede steal the cookie?
B: Yes. / Yes, he did.

The idea is that with antecedent assertions, a yes answer could, in principle, just express compliance, similar to okay. If the speaker intends the stronger reading that he himself is committed towards the proposition, then the more specific answer yes he did is preferred. The compliance reading of yes, and the non-compliance reading of no, can be derived as follows: Assume that the operator CG expresses that a proposition, here 'Ede stole the cookie', is part of the common ground. The discourse referent $\mathrm{d}^{\prime}$ in (45) then would be propositional, and yes and no could be understood just as in (31): yes asserts that the proposition 'Ede stole the cookie' indeed is in the common ground; notice that this does not commit speaker B to the truth of this proposition. And no would assert that it is not; again, $\mathrm{B}$ would not be committed to the truth of the negation of the proposition; B could just express that there aren't sufficient reasons to assume B. This use of no could also explain the no of surprise, as in No!, equivalent to That's not true! that, without really challenging the authority of the speaker, expresses an unwillingness to accept a proposition into the common ground without further elaboration.

There are also paralinguistic ways of responses, that is, ways that do not correspond to the standard phonology of English (cf. Ward 2006). There is what the OED literalizes as $u h$-huh, often with raising tone pattern, and as $u h-u h$, with glottal stops and downstep tone pattern. In contrast to okay, uh-huh can be used as an answer to a polarity question, just as $u h$-uh, cf. (47).

A: Did Ede steal the cookie? B: Uh-huh. / Uh-uh. / * Okay. 
Response particles as propositional anaphors

The use of $u h$-huh and $u h-u h$ as reactions to questions shows that these responses can commit the utterer to a proposition. This is also evident for $u h-u h$ as a negative response to an assertion, as in (48):
A: Ede stole the cookie.
B: Uh-uh. (equivalent to no, he didn't).

The status of $u h$-huh as a response to an assertion appears to be ambiguous between compliance reading, like okay, and the committing reading as in (47). However, just as the simple yes, cf. (46a), the committing interpretation of $u h$-huh is somewhat marginal in this case, and eclipsed by the complying interpretation, perhaps even more so than yes.

We can summarize these observations by the hypothesis that $u h-h u h$ and $u h$ $u h$ mean the same as yes and no. However, the syntactic categories are clearly distinct; responses like uh-huh, he did or uh-uh, he didn't are rather unusual. These paralinguistic response particles also cannot occur in embedded positions in German, as in conditional clauses or as complements of propositional attitude verbs, different from $j a$ and nein, cf. wenn ja, but *wenn uh-uh. The relation between these paralinguistic signals to yes and no are similar to huh? vs. what? in requests for repeating a prior utterance.

In concluding this section, it should be pointed out that in addition to verbal responses, there are also non-verbal ones, e.g. the head nod for agreeing answers and the head shake for non-agreeing answers in Western European cultures. In general, the range of such reactions to different kinds of speech acts is a field still largely unexplored in formal semantics and pragmatics.

\section{Optimal Choice of Polarity Particles}

In the preceding section I have proposed that response particles, in particular yes and no, pick up propositional discourse referents and assert them, or assert their negation. In this section we will consider the optimal choice of such particles, in particular with negated antecedent clauses.

\subsection{Yes and no as responses to negated propositions}

Recall the analysis of assertions of negated clauses. In (49), only the propositional discourse referents introduced by the TP and the NegP are indicated.

$$
\text { [ActP ASSERT } \underset{\hookrightarrow \mathrm{d}_{\text {prop }}}{[\mathrm{Negp}} \text { Ede did-n't [TP } \stackrel{\mathrm{t}_{\text {Ede }}}{\leftrightarrow \mathrm{t}_{\text {did }} \text { steal the cookie]]] }}
$$

The response particles yes and no can pick up either discourse referent, $\mathrm{d}^{\prime}$ or $\mathrm{d}$, resulting in four possible analyses. As we have seen before, some of these interpretations require an additional elliptical clause or a particular rejecting accent. 
(50) a. Yes. ASSERT(d') 'Yes, he did!' Rejecting accent, with clause.

b. Yes. ASSERT(d) 'Yes, he didn't.' Natural, but with clause.

c. No. ASSERT( $\left.\neg \mathrm{d}^{\prime}\right)$ 'No (he didn't).' Natural, clause not necessary.

d. No. ASSERT $(\neg \mathrm{d})$ 'No, he did!' Rejecting accent, with clause.

How can we explain these preferences? I suggest that there are two pragmatic markedness principles that are operative which jointly generate the observed pattern. First, disagreement with the first speaker must be marked; this explains the rejecting accent pattern and the strong tendency to use the response particles together with an elliptical clause. Second, the two propositional discourse referents differ in their salience. One would perhaps be inclined to think that the NegP referent, $d$, is more salient than the TP discourse referent, $d^{\prime}$, as the latter is introduced within the scope of the expression that introduces d. However, in typical cases in which a negated clause is asserted, the non-negated proposition will already be salient in the context. For example, it is hard to imagine that a sentence like Ede didn't steal the cookie could be uttered in a context in which the proposition 'Ede stole the cookie' is not salient already, e.g. as a possible explanation why the cookie is lacking. Hence we can assume the following two constraints:

(51) a. *NeGDR: Penalizes picking up a negatively marked discourse referent.

b. *DisAgr: Penalizes disagreement with the other speaker.

The competition between the two constraints can be visualized in an OT tableau. We can plausibly assume that violations of *DISAGR are ranked higher than violations of $* \mathrm{NEGDR}_{\text {. }}$

(52) Calculation of optimal forms in an OT tableau, antecedent: assertion (49).

\begin{tabular}{|c|c|c|c|c|c|c|}
\hline & expression & reference & resulting meaning & *DISAGR & *NEGDR & Favorite \\
\hline $\mathrm{a}$ & yes & $\mathrm{d}^{\prime}$ & 'He did.' & $*$ & & $((\bar{\Xi}))$ \\
\hline b & yes & $\mathrm{d}$ & 'He didn't.' & & $*$ & (घ) \\
\hline c & no & $\mathrm{d}^{\prime}$ & 'He didn't.' & & & छ] \\
\hline $\mathrm{d}$ & no & $\mathrm{d}$ & 'He did.' & $*$ & $*$ & \\
\hline
\end{tabular}

The optimal candidate is no in (c). This predicts that the simple response particle no will have this reading. Hence if no should express reading (d), it must be specified with an elliptical clause. For yes, we have a ranking-dependent preference for (b) over (a). This predicts that yes will be preferably used with the same interpretation as no. But as the two interpretations in (a) and (b) differ only slightly, a clarifying elliptical clause is usually required to express these meanings.

What about yes and no as responses to questions with propositional negations? Such questions also introduce two discourse referents: 
Response particles as propositional anaphors

$$
\begin{gathered}
\text { [ActP } \operatorname{did} \text { QUEST [NegP Ede not } \\
\qquad \mathrm{d}_{\text {prop }} \\
\left.\left.\left.\hookrightarrow \mathrm{T}_{\text {Ede }} \text { steal the cookie }\right]\right]\right] ?
\end{gathered}
$$

The reactions are similar as to negated assertions, except that yes is more naturally interpreted as 'he did' (cf. Holmberg 2012). This would follow from the plausible assumption that questions based on negated propositions do express a bias, but a weaker one than assertions. Hence the constraint *DIsAGR is ranked lower, leading to a preference for line (a) over line (b) in diagram (52).

The preference for the non-negated discourse referent $\mathrm{d}^{\prime}$ was motivated by the fact that negated antecedent clauses typically occur in contexts in which the nonnegated proposition is salient. In contexts in which this condition is not satisfied, we should expect the answer patterns to be different. This is indeed the case:

(54) B: Which of the mountains on this list did Reinhold Messner not climb?

A: Well, let's see... He did not climb Mount Cotopaxi in Ecuador.

B: Yes. (= he didn't climb it) / No. (= he climbed it)

Here the negated discourse referent $d$ now is more salient. When we assume instead of $* \mathrm{NEGDR}_{\mathrm{B}}$ a constraint $*$ NoNSAL which penalizes reference to less-salient discourse referents, this would result in yes meaning 'he didn't' as the most optimal answer. Polarity questions containing a focus as in (55) make the same point: ${ }^{4}$

$$
\text { A: Did BILL not brush his teeth? B: Yes. (= he didn't)/No. (= he did) }
$$

\subsection{Responses to questions with syntactically high negation}

There is another type of negation in questions, first identified by Ladd 1981, in which negation occurs at a syntactically higher position, as in (56).

$$
\begin{aligned}
& \text { A: Didn't Ede steal some cookie? } \\
& \text { [ActP } d i d-R E Q U \text { [NegP } n o t \text { [ActP ASSERT [ }{ }_{\mathrm{TP}} \text { Ede } \mathrm{t}_{\mathrm{did}} \text { steal some cookie]]]] } \\
& \hookrightarrow \mathrm{d}_{\text {prop }}
\end{aligned}
$$

The syntactic analysis (56) captures Ladd's intuition that the negation in such questions is not propositional negation. It follows Krifka (to appear), who argues that with such questions, a speaker requests the denegation of an assertion. In the case at hand, the speaker asks the addressee to exclude the assertion that Ede stole some cookies. This move can be performed, for example, when the speaker is inclined to believe that Ede stole some cookies, and wants to check whether the addressee would comply with this by eliminating any reason to assert the opposite.

What is important for our purpose is that negation is interpreted at the level of speech acts, and not as propositional negation. Hence no propositional discourse referent for the negated proposition is introduced. Hence such questions are similar to assertions, and we do not find any ambiguity for the answers yes and no:

4 Cf. also Tian e.a. (2010) concerning the non-linguistic accessibility of situations in simple negated sentences and in negated cleft sentences. 

B: a. Yes (he did).
b. No (he didn't).
c. *No, he did.
d. *Yes, he didn't.

\subsection{Polarity particles in German: the role of doch}

In addition to yes and no there is a third particle in German, doch (cf. also French si), that requires the presence of a negated propositional discourse referent ${ }^{5}$, as the following examples illustrate, where (57b) contains a negation, nicht.

(58) a. A: Ede hat den Keks gestohlen. B: Ja. / Nein. /*Doch.

b. A: Ede hat den Keks nicht gestohlen. B: Ja. / Nein. / Doch.

The negated discourse referent must be introduced with a sentential category. cf. (59). And just like ja and nein, doch can also occur in embedded clauses, cf. (60).

(59) A: Es fehlt ein Keks. 'A cookie is missing.' B: Ja. / Nein. / *Doch.

(60) Ede hat den Keks wohl nicht gestohlen. Falls doch, wird er bestraft.

'Ede probably did not steal the cookie. But if he did, he will be punished.'

As for the meaning of doch, I assume that doch presupposes that two propositional discourse referents are salient, one the negation of the other, and that doch takes up the non-negated discourse referent and asserts it (cf. Karagjosova 2006, who argues that doch contrastively focuses on a proposition $\mathrm{p}$, requiring an alternative set $\{p, \neg p\}$ ). As argued for in (29), negated discourse referents can be identified due to a feature [neg]. Alternatively, we might say that doch picks up the negated discourse referent and negates it. But in this case nominal discourse referents that are introduced in the antecedent clause would not be accessible after doch picks up that discourse referent, as negation limits the lifespan of discourse referents. But in fact they are:

(61) Ede hat wohl k-einen Keks gestohlen. Wenn doch, müssen wir ihn finden.

'Ede may not have stolen a cookie. If $\mathrm{DOCH}$, we have to find $\underline{\text { it.' }}$

The specific presupposition of doch (expressed by a constraint Pres) creates a competition with the particles yes and no. In particular, the use of the particle yes for picking up the non-negated discourse referent is blocked by doch. This can be expressed in OT tableaux in the fashion of Beaver 2004, who treats a similar situation, the blocking of taking up salient discourse referents by simpler expressions. Following Beaver, I assume a meta-constraint BLOCK that is marked by the presence of an expression for which the indicated interpretation is strongly preferred.

(62) Optimal forms in an OT tableau; negated antecedent clause in German;

DisAgr is irrelevant if ordered under BLocK.

5 This negated discourse referent can be accomodated in the "confirming" use of doch, as in Das war nett von Ihnen. Doch, das muss man sagen 'This was nice of you. DOCH one has to say that', where doch anticipates a negation of the first clause (cf. Karagjosova 2006). 
Response particles as propositional anaphors

\begin{tabular}{|l|c|c|c|c|c|c|l|}
\hline & expression & reference & meaning & *PRES & BLOCK & *NeGDR & Favorite \\
\hline $\mathrm{a}$ & $j a$ & $\mathrm{~d}^{\prime}$ & 'He did.' & & $*$ & & \\
\hline $\mathrm{b}$ & $j a$ & $\mathrm{~d}$ & 'He didn't.' & & & $*$ & $($ घ) \\
\hline $\mathrm{c}$ & nein & $\mathrm{d}^{\prime}$ & 'He didn't.' & & & & $\Xi$ \\
\hline $\mathrm{d}$ & nein & $\mathrm{d}$ & 'He did.' & & & $*$ & $(\Xi)$ \\
\hline $\mathrm{e}$ & doch & $\mathrm{d}$ & 'He did.' & & & & $\Xi$ \\
\hline $\mathrm{f}$ & doch & $\mathrm{d}$ & 'He didn't.' & $*$ & & $*$ & \\
\hline
\end{tabular}

This tableau predicts the right answer patterns. The additional particle doch creates a more expressive system, obviating the need to add an elliptical clause, as in English, where this appears to be a Celtic feature, cf. Vennemann 2009.

\subsection{Narrow-scope negation and alternative questions}

Let us look at the following construction concerning negation in the scope of quantifiers. Holmberg 2012 observes preference for the agreeing answer in (63):

\section{A: John sometimes / purposely did not show up for work. \\ B: Yes, he didn't. / 'No, he didn't.}

This can be explained as negation under the scope of a quantifier does not result in a NegP, but in predicate negation, hence does not introduce a negated propDR.

Predicate negation might also explain response systems like the one of Japanese. The response particles hai and iie are often explained as particles that express agreement vs. disagreement. Following Yabushita 1998, the difference rather is in the nature of negation, which he argues to be predicate negation in Japanese. Hence only one discourse referent is introduced in negated clauses, and the response particles hai and iie, interpreted like yes and no, lead to a non-ambiguous interpretation even if the antecedent clause contained a negation.

The second construction are alternative questions. They are typically not based on a questioned proposition, hence do not allow for yes/no answers at all:

\section{A: Did Ede steal the cookie or the lollipop? \\ B: *Yes. /*No. / The lollipop.}

Answers yes and no are not possible in alternative questions with sentential alternatives as in (65). Here, propositional discourse referents are introduced, but in a completely parallel fashion. Consequently, yes and no would be ambiguous, in a way that cannot be recovered by pragmatic optimization.
A: [Is the door open], or [is it closed]? $\hookrightarrow \mathrm{d}_{\text {open }} \rightarrow \mathrm{d}_{\text {closed }}$
B: \#No. / \#Yes. / It is open. 
But as Farkas \& Roelofsen (2012) observe, the answer no is quite good in (66), where the second alternative is the sentential negation of the first.

$$
\begin{aligned}
& \mathrm{A}:\left[\text { Is the door } \left[\mathrm { t } _ { \mathrm { door } } \text { open] or [is } \left[\mathrm{NegP} \text { not [ } \mathrm{t}_{\mathrm{door}}\right.\right.\right. \\
& \text { B: (?)No. /(?) Yes. } \\
& \hookrightarrow \mathrm{d} 1_{\text {open }} \quad \hookrightarrow \mathrm{d} 2^{\prime}\left[\text { neg] } \rightarrow \mathrm{d} 2_{\text {open }}\right.
\end{aligned}
$$

The reason why yes and no are acceptable is that they would result in the same information when applied to either disjunct. In the first disjunct, only one propositional discourse referent is introduced, $\mathrm{d} 1$; in the second, there are two propositional discourse referents, where $\mathrm{d} 2$ is preferred over $\mathrm{d} 2{ }^{\prime}$. But notice that $\mathrm{d} 1$ and $\mathrm{d} 2$ are anchored to the same proposition, and hence picking up either one by yes or no would convey the same meaning.

\section{References}

Asher, Nicholas. 1986. Belief in discourse representation theory. Journal of Philosophical Logic 15: 127-189.

Beaver, David. 2004. The optimization of discourse anaphora. Linguistics and Philosophy 27: 1-53.

Cohen, Ariel \& Manfred Krifka. 2011. Superlative quantifiers as modifiers of meta-speech acts. The Baltic International Yearbook of Cognition, Logic and Communication 6: 1-56.

Cooper, Robin \& Jonathan Ginzburg. 2011. Negation in dialogue. SemDial 11. 130-139.

Cornish, Francis. 1992. So be it: the discourse-semantics of so and it. Journal of Semantics 9: 163-178.

Farkas, Donka F. 2010. The grammar of polarity particles in Romanian. In: Di Sciullo, Anna Maria \& Virginia Hill, (eds), Edges, Heads and Projections. Interface Properties. John Benjamins, 87-124.

Farkas, Donka F. \& Kim B. Bruce. 2010. On reacting to assertions and polar questions. Journal of Semantics 27: 81-118.

Farkas, Donka F. \& Floris Roelofsen. 2012. Polar initiatives and polar particle responses in an inquisitive discourse model. Ms, University of Amsterdam.

Frank, Annette. 1996. Context Dependence in Modal Constructions. Doctoral dissertation. Universität Stuttgart.

Geurts, Bart. 1998. Presuppositions and anaphors in attitude contexts. Linguistics and Philosophy 21: 545-601.

Ginzburg, Jonathan \& Ivan A. Sag. 2000. Interrogative Investigations. Stanford, Ca.: CSLI Publications.

Heim, Irene. 1992. Presupposition projection and the semantics of attitude verbs. Journal of Semantics 9: 183-221. 
Response particles as propositional anaphors

Holmberg, Anders. 2012. On the syntax of yes and no in English. Newcastle Working Papers in Linguistics 18: 52-72.

Karagjosova, Elena. 2006. The German response particle doch as a case of contrastive focus. Ninth Symposium on Logic and Language (LoLa9), 90-98

Kamp, Hans \& Uwe Reyle. 1993. From Discourse to Logic. Introduction to Model Theoretic Semantics of Natural Language, Formal Logic, and Discourse Representation Theory. Dordrecht: Kluwer.

Kramer, Ruth \& Kyle Rawlins. 2009. Polarity particles: an ellipsis account. NELS 39.

Krifka, Manfred. 2001. For a structured account of questions and answers. In: Féry, Caroline \& Wolfgang Sternefeld, (eds), Audiatur Vox Sapientiae. A Festschrift for Achim von Stechow. Berlin: Akademie-Verlag, 287-319.

Krifka, Manfred. to appear. Negated polarity questions. In: Lee, Chungmin \& Ferenc Kiefer (eds), Contrastiveness and Scalar Implicature. Berlin: Springer. http://amor.cms.hu-berlin.de/ h2816i3x/Publications/NegatedPolarityQuestions.pdf

Ladd, D. Robert. 1981. A first look at the semantics and pragmatics of negative questions and tag questions. Chicago Linguistic Society 17. Chicago: 164-171.

Pollock, Jean-Yves. 1989. Verb movement, universal grammar, and the structure of IP. Linguistic Inquiry 20: 365-424.

Servidio, Emilio. 2012. Polarity particles in Italian fragment answers. Internet Celebration for Luigi Rizzi's 60th Birthday.

Szabolcsi, Anna. 1982. Model theoretic semantics of performatives. In: Kiefer, Ferenc, (ed), Hungarian Linguistics. Amsterdam: John Bejamins, 515-535.

Tian, Ye, Richard Breheny \& Heather J. Ferguson. 2010. Why we simulate negated information: A dynamic pragmatic account. Quarterly Journal of Experimental Psychology 63: 2305-2312.

Vennemann, Theo. 2009. Celtic influences in English? Yes and No. English Language and Linguistics 13: 309-334.

Ward, Nigel. 2006. Non-lexical conversational sounds in American English. Pragmatics \& Cognition 14: 129-182.

Yabushita, Katsuhiko. 1998. Why do Japanese hai and iie not behave like English yes and no all the way? Kansas Working Papers in Linguistics 23: 59-74.

Zeijlstra, Hedde. 2004. Sentential Negation and Negative Concord. Dissertation. Utrecht: University of Utrecht.

Manfred Krifka

Institut für deutsche Sprache

und Linguistik

Humboldt-Universität zu Berlin

D-10099 Berlin, Germany

krifka@rz.hu-berlin.de
Zentrum für Allgemeine Sprachwissenschaft (ZAS)

Geisteswissenschaftliche Zentren Berlin

Schützenstraße 18

D-10117 Berlin, Germany 